\title{
Study Nanostructure of a Biomaterial with Medicine Therapeutic Activity
}

\author{
Marilú Chávez-Castillo1* ${ }^{*}$ Martha Lilia Domínguez-Patiño², Rosa María Melgoza-Alemán² \\ ${ }^{1}$ Centro de Investigación en Ingeniería y Ciencias Aplicadas, Universidad Autónoma del Estado de Morelos, \\ Cuernavaca, México \\ ${ }^{2}$ Facultad de Ciencias Químicas e Ingeniería, Universidad Autónoma del Estado de Morelos, Cuernavaca, \\ México \\ Email: "mariluch@uaem.mx
}

Received 13 February 2016; accepted 12 April 2016; published 15 April 2016

Copyright (C) 2016 by authors and Scientific Research Publishing Inc.

This work is licensed under the Creative Commons Attribution International License (CC BY).

http://creativecommons.org/licenses/by/4.0/

(c) (i) Open Access

\section{Abstract}

In Mexico, the medicinal plants have been for used since ancient times and still continue to use by rural populations to treat conditions such as infectious diseases (skin, gastrointestinal or respiratory), metabolics, inflammatory problems, among others. This work includes a proposal that initiates the study and development of new biomaterials or vehicles with therapeutic application. The nanomolecular interaction of the organic extract of a plant (EOV) Distictis buccinatoria (dc) with different materials inert supports of inorganic type (bentonite, gel) determining their and combined anti-inflammatory activity is studied individually [1] [2]. The importance of the characterization of biomaterials by scanning electron microscopy (SEM) is ability to analyze the structure on the surface of materials (organic, inorganic and biological) in the micro and nanometrics levels in order to correlate it with the sample surface properties such as roughness, interfacial phenomena, etc. With this technique we can also perform the chemical analysis at different levels (micro and nano) for information on the nature and composition of the materials [3] [4]. The biomaterial shows that higher anti-inflammatory activity is to be generated through the combination of EOV-gel, the nanostructure interaction SEM shows integrated particles agglome-rated form and porous due to the presence of EOV and some flat areas indicated the gel preponderance situation generated by the low interaction between materials of organic type and polar type (gel).

\section{Keywords}

Biomaterials, Nanomolecular, Anti-Inflamatory, Vehicles

\footnotetext{
*Corresponding author.
}

How to cite this paper: Chávez-Castillo, M., Domínguez-Patiño, M.L. and Melgoza-Alemán, R.M. (2016) Study Nanostructure of a Biomaterial with Medicine Therapeutic Activity. Microscopy Research, 4, 32-38. 


\section{Introduction}

The science and the art to choose the primary materials which the drugs are prepared, dates back to Roman age [5]-[7]. Today, a new aspect in preparing new generation of drugs has led to propose that they are prepared or produced from new and novel biomaterials with therapeutic activity [8] [9]. The study of biomaterials is systematically established and oriented prototypes and medical devices. Recently it has been proposed the design and study of new biomaterials for therapeutic use, which are built from plant extracts and organic materials inert inorganic type [10]-[12].

This paper looks at this innovative approach to the creation and design of a biomaterial that involves the use of a vegetable organic extract from the medicinal plant known by the common name of Tonacaxóchitl (Distictis bucinatoriadc) [13]-[15] which is widely used in medicine alternatively northeastern state of Morelos to try and counteract inflammatory ailments [16]. A bio-chemical study targets established that the organic extract dichloromethane Tonacaxóchitl has anti-inflammatory activity in mouse induced edema TPA (13-acetate 12-orthodecanoilforbol) [17] [18]. It is also established that the major component present in the organic extract corresponds to ursolic acid, as discussed by [19] [20]. These studies suggest allowed nanomolecular study interaction for generating a biomaterial with therapeutic activity, using as active ingredient the organic extract combined with dichloromethane Tonacaxóchitl different inert supports of inorganic type (bentonite, gel), to select the vehicle to allow the proper handling and controlled release of organic extract in the tissue to be treated, to study their individual and combined anti-inflammatory activity. As discussed by [21] [22].

\section{Methodology}

The plant extract (dc) was obtained by solution with dichloromethane [23], the resulting biomaterial characterization was performed by scanning electron microscopy (SEM). Which allows analyzing the surface structure of materials (organic, inorganic and biological), in the micro and nanometric levels in order to correlate with surface nanointeraction sampling properties, such as roughness, interfacial phenomena, etc. [24]. This technique allowed also performs chemical analysis at different levels (micro and nano) for get information about the nature and composition of the biomaterial. The scanning electron microscope may be equipped with different sensors, among which may be mentioned: A secondary electron detector for high resolution images SEI (Secondary Electron Image) a backscattered electron detector which allows the imaging composition and topography of the BEI (backscattered Electron Image) surface and an energy dispersive detector EDS (Energy Dispersive). As mentioned in the thesis.

By the power of resolution and large depth of field of SEM and EDS X-ray analyzer, the work done in our laboratory confirms that these methods of analysis are of increasing importance and applications in various disciplines of science: materials science, morphological and analytical characterization of biomaterials, study of surfaces, textures and irregular segregation.

\subsection{Technique Sample Preparation}

In general, the sample preparation is simple and the requirements are: fixation, dehydration, drying; furthermore, the surface should be conductive of electrical current. The latter requirement is fulfilled in metals but not in biological samples, so that they are coated with a layer of coal or gold/palladium, according to the conditions in which the sample and the main objective of the study is to work, i.e., to be analyzed by EDS or to be seen under a microscope. Before treating the samples should be taken into account the material to be observed and guided by specific parameters for each sample.

\subsubsection{Sample Preparation for SEM Observation}

The test sample must be completely dry and powder, is placed in a sample holder graphite tape in which powders are placed evaporated with the use of a white gold-palladium metal to obtain samples for structural observation a scanning electron microscope.

\subsubsection{Sputtering Preparation Process}

After that comes the deposition by sputtering, the simplest is that corresponding to a diode comprising two electrodes immersed in a gas at low pressure that applies a high DC potential, thereby generating a shock. 
Due to the strong difference in potential between the two electrodes, the ionization of the process gas occurs. In this configuration, the electric field strength near the cathode is high, so that the potential drop occurs practically in a region near the cathode surface. The rest of the space between the cathode and anode plasma occupies, with the potential gradient in this area practically nil. The dimensions of this small area are usually in the order of the mean free path of electrons in the gas.

When the ions collide with the cathode, besides other material erosion effects occur, such as the secondary ion emission, light emission, secondary electron emission, etc. Part of the electrons is re-generated ions combine with and cause light emission of the cathode surface. The secondary electron emission contributes to increasing the degree of ionization of the plasma and therefore causes more intense bombardment. This effect is used to increase process efficiency, using magnets to confine the movement of these secondary electrons. The sputtering process takes place in the vacuum chamber. To prevent the residual gas causes considerable contamination in deposited coatings must get a high vacuum (vacuum is considered high for the sputtering process pressures as discussed elsewhere.

\section{Results and Discussion}

Now we show the images obtained gel substrates, and particles of extract powder (bentonite) taken with secondary electrons: Images obtained with secondary electrons are useful for surveying and their paths are curved, so that the image is soft and diffuse shadows; in the background the depressions or hidden areas (produce less detectable electrons) are observed. These facts should be considered when analyzing the images obtained.

\subsection{Micrographs of the Vehicle Gel}

The following images (Figure 1, Figure 2) are presented detail image of an area where we can see the gel substrate layers with flat shapes and rolled to a thickness of about 5 microns and some grooves inside each layer it is presented.

The image (Figure 2) shows a panoramic visualization where we can see large accumulated amount of gel shaped reef with some areas of laminar aspect is presented.

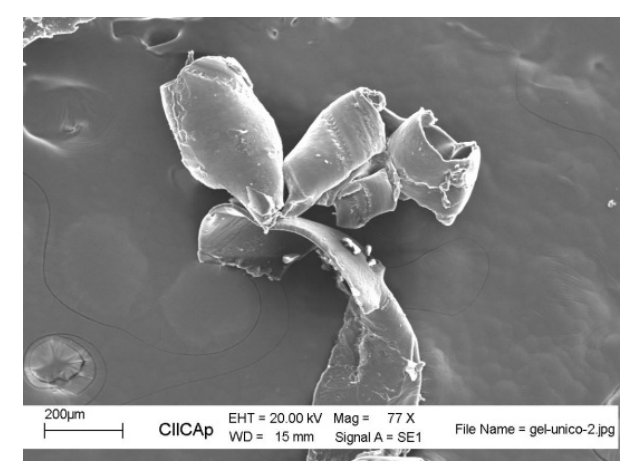

Figure 1. Micrography showing the cutting of a layer of gel.

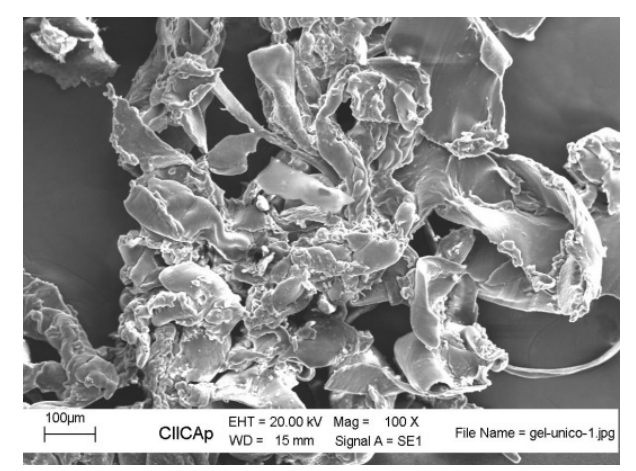

Figure 2. Micrography showing the cutting of a layer of gel. 


\subsection{Micrographs of EOV}

Solid areas porous zones and areas of fibrous appearance: In Figure 3, a panoramic image of the extract which features various areas of different morphological aspects are observed.

Figure 4 shows an image where the extract has a large amount of mixing between solid areas and porous zones, while the particle size is observed within the solid area is about 1 micron is observed.

\subsection{Micrography of Material Bentonite}

Figure 5 shows a panoramic image of the sample is presented in powder form which types of irregular grains sizes less than 100 microns are observed.

Figure 6 shows a detail of the powder where large particles of about 50 microns and smaller particles were observed occurs.

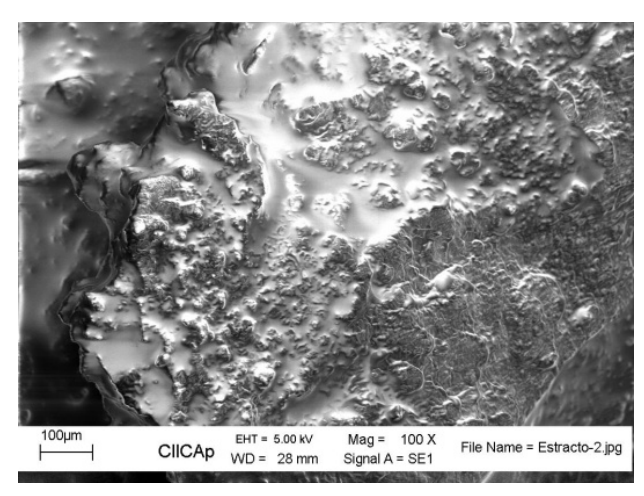

Figure 3. Micrography plant extract.

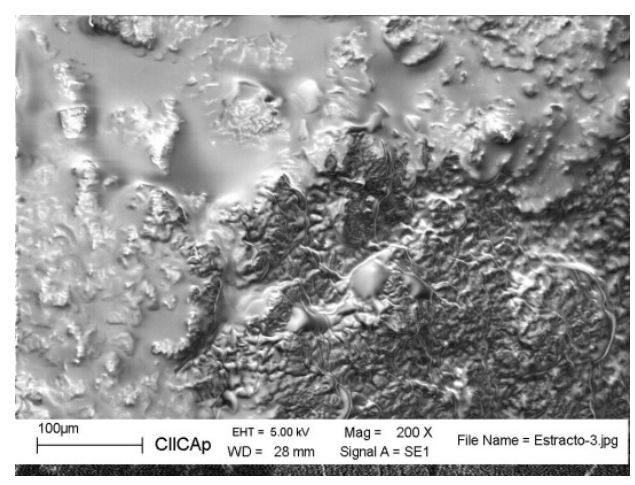

Figure 4. Micrography plant extract.

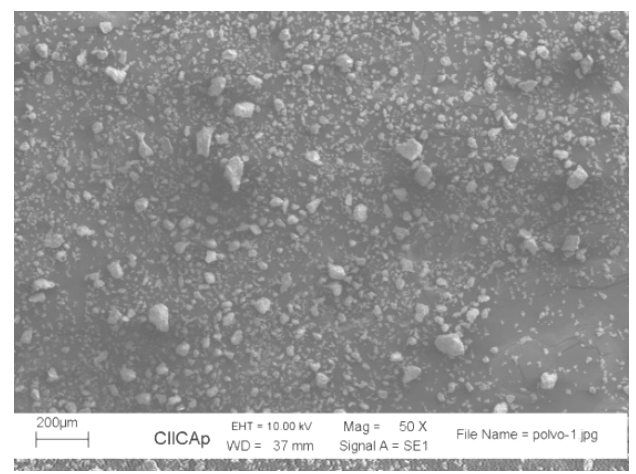

Figure 5. Micrography of the organic material bentonite. 


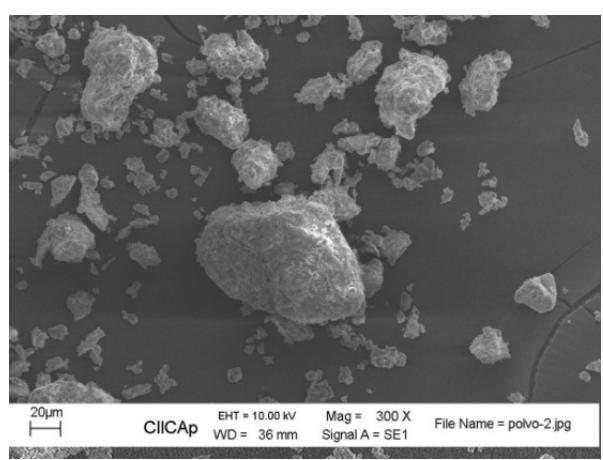

Figure 6. Micrography of the organic material bentonite.

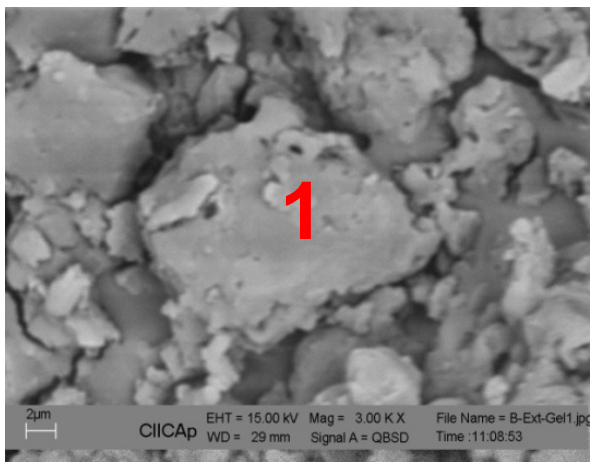

(a)

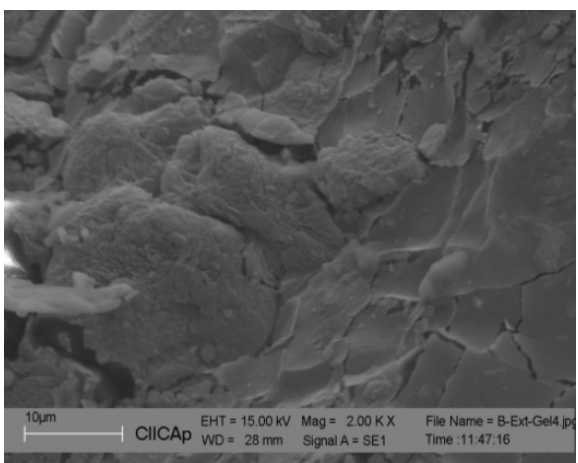

(b)

Figure 7. (a)-(b) Image biomaterial technical secondary electron.

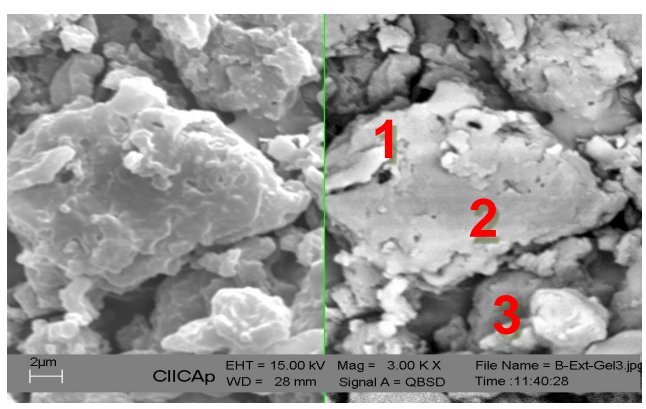

(a)

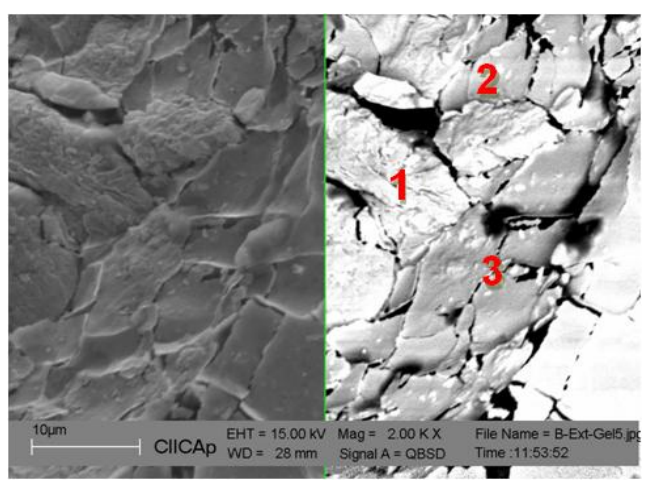

(b)

Figure 8. (a) Image technique material backscattered electrons. (b) Image technique material backscattered electrons. 


\subsection{Microstructural Characterization of the Differences between the Materials Forming the Biomaterial}

Images secondary electron and backscattered to observe the differences in the materials forming the biomaterial electrons are shown in the following figures.

In Figure 7(a)-(b), we can observe a contrast of a white phase where the elemental analysis (DS) containing carbon and oxygen occurs is observed, it suggests that it is a gel phase, as indicated.

While in the part indicated with the number 2 image in Figure 8(a) and Figure 8(b), a contrast of gray tones which was conducted elemental analysis and elements such as obtained is observed: $\mathrm{C}, \mathrm{O}, \mathrm{Mn}, \mathrm{Zn}, \mathrm{Fe}, \mathrm{Al}, \mathrm{Cr}$, $\mathrm{Mg}$, where the predominant elements were the $\mathrm{C}$ and $\mathrm{O}$ while gold and palladium was part of this evaporation is credited with bentonite phase. However, in Section 3 of the image a dark tone which represents us by carbon elemental analysis suggests that this is a phase the organic plant extract (EOV) is observed.

\section{Conclusions}

The nanostructure interaction of SEM showed integral particles agglomerated form, porous due to the presence of the organic plant extract and some flat areas indicated the majority presence of the gel situation generated by the low interaction between materials of organic nature and polar type (gel).

The biomaterial showed greater anti-inflammatory activity. It was generated by combination of gel and EOV. A further alternative as support material for the extract was the gel because the antiinflammatory activity of the dc plant is unaffected by the presence of this and incorporated favorably as biomaterial as shown in the micrographs shown.

\section{Acknowledgements}

The author would like to thank Ms. Ferrer and Mr. Herrera for their suggestions and support and Biomedical Research Center South Xochitepec, Morelos; México.

\section{Conflict of Interest}

The authors declare that there is no conflict of interests regarding the publication of this paper.

\section{References}

[1] Monroy, C. and Castillo, P. (2000) Enciclopedia Plantas medicinales utilizadas en el estado de Morelos. Universidad Autónoma del Estado de Morelos, México, 400 p.

[2] Rojas, M.G. (2001) Antimicrobial Evaluation of Certain Plants Used in Mexican Traditional Medicine for the Treatment of Respiratory Diseases. Journal of Ethnopharmacology, 74, 97-101. http://dx.doi.org/10.1016/S0378-8741(00)00349-4

[3] Navarro, A., de la Heras, B. and Villar, A. (2001) Anti-Inflamatory and Inmunomodulating Properties of a Sterol Fraction from Sidensfoetens CLEM. Biological and Pharmaceutical Bulletin, 24, 470-473. http://dx.doi.org/10.1248/bpb.24.470

[4] Goldstein, N. (1992) Scanning Electron Microscopy and X-Ray Analysis. Plenum Press, New York. http://dx.doi.org/10.1007/978-1-4613-0491-3

[5] Warner, T.D. (2004) Cyclooxygenases: New Forms, New Inhibitors, and Lessons from the Clinic. The FASEB Journal, 18, 790-804. http://dx.doi.org/10.1096/fj.03-0645rev

[6] Argueta, A. (1994) Atlas de las Plantas de la Medicina Tradicional Mexicana. Tomo 1-3, Instituto Nacional Indigenista, México D.F., 1786 p.

[7] Abraham, G.A. (1998) La ciencia y la ingeniería de los biomateriales, un desafío interdisciplinario. Ciencia Hoy, 9, 5059.

[8] Cuadrado, T.T. (1996) Ciencia y Mercado de Biomateriales, situación actual y perspectivas. Materiales Ciencia y Mercado, 2, 47-52.

[9] González, M.F. (1998) Polímeros bioadsorbibles en dispositivos biomédicos. Argent de Bioing, 4, 3-10.

[10] Ratner, B.D. (1996) Biomaterials Science and Introduction to Materials in Medicine. Academic Press, Cambridge.

[11] Gustavo, A. (2001) Hacia nuevos biomateriales: Aportes desde el campo de la Química Macromolecular. Anales de la 
Real Sociedad Española de Química, No. 2, 22-33.

[12] Gentry, A.H. (1982) Flora de Veracruz. Instituto Nacional de Investigaciones sobre recursos bióticos Xalapa, Veracruz, México. Fascículo 24, 1-4.

[13] Rëmi, S. (1977) Diccionario de la Lengua Nahualt o Mexicana. Siglo XXI, México, D.F., p. 715, 774.

[14] Thompson, W.A.R. (1981) Guía práctica ilustrada de las plantas medicinales. Ed. Blume, Barcelona, 219.

[15] Gentry, A.H. (1992) A Sinopsis of Bignoniaceae, Ethnobotany and Economic Botany. Annals of the Missouri Botanical Garden, 79, 53-64. http://dx.doi.org/10.2307/2399809

[16] Rojas, M.G. (2007) Antibacterial, Antifungal, and Cytotoxic Activities of Distictis buccinatoria. Pharmaceutical Biology, 45, 289-294. http://dx.doi.org/10.1080/13880200701214847

[17] De Young, L.M. (1989) Edema and Cell Infliltration in the Phorbol Ester-Treated Mouse Ear Are Temporally Separate and Can Be Differentially Modulated by Pharmacologic Agents. Agents and Actions, 26, 335-341. http://dx.doi.org/10.1007/BF01967298

[18] Liu, J. (1995) Pharmacology of Oleanolic Acid and Ursolic Acid. Journal of Ethnopharmacology, 49, 57-68. http://dx.doi.org/10.1016/0378-8741(95)90032-2

[19] Liu, J. (2005) Oleanolic Acid and Ursolic Acid. Research Perspectives. Journal of Ethnopharmacology, 100, 92-94. http://dx.doi.org/10.1016/j.jep.2005.05.024

[20] Yasunaka, K. (2005) Antibacterial Activity of Crude Extracts from Mexican Medicinal Plants and Purified Coumarins and Xantrhones. Journal of Ethnopharmacology, 97, 293-299. http://dx.doi.org/10.1016/j.jep.2004.11.014

[21] Steinberg, M. (2001) From Inactive Ingredients to Pharmaceutical Excipients. Pharmaceutical Technology, 25, 62-64.

[22] Blecher, L. (1993) Pharmaceutical Excipients, Producers and Users Strengthen Their Voice. Pharmaceutical Technology, 17, 38-39.

[23] Chávez, C.M. (2008) Desarrollo de biomateriales con aplicación terapéutica medicinal. PhD Thesis, Centro de Investigación en Ingeniería y Ciencias Aplicadas, México, D.F.

[24] Guardián, T.R. (2010) Modificación superficial de aceros de aplicación industrial. PhD Thesis, Centro de Investigación en Ingeniería y Ciencias Aplicadas, México, D.F.

Table of Abbreviations

\begin{tabular}{cc}
\hline EOV & Extractorganic Vegetal \\
DC & Distictis bucinatoria \\
SEM & Scanning Electron Microscopy \\
TPA & 13-Acetate 12-ortho-decanoilforbol \\
SEI & Secondary Electron Image \\
BEI & Backscattered Electron Image \\
EDS & Energy dispersive detector \\
\hline
\end{tabular}

